\title{
Erratum to: Different physiological responses influenced by salinity in genetically related Dunaliella salina isolates
}

José Alberto Narváez-Zapata •

Rafael Rojas-Herrera • Yamilka López-Uc •

Leticia Sánchez-Estudillo

Published online: 26 March 2011

(C) Springer Science+Business Media B.V. 2011

\section{Erratum to: Biotechnol Lett \\ DOI 10.1007/s10529-011-0523-x}

The accession numbers for the Dunaliella salina isolates reported in this study are FJ360756,
FJ360757 and FJ360758 for DUNS-1, -2 and -3, respectively, both in the text and in Fig. 4.

The online version of the original article can be found under doi:10.1007/s10529-011-0523-x.

J. A. Narváez-Zapata $(\bowtie)$ · Y. López-Uc

Centro de Biotecnología Genómica, Instituto Politécnico Nacional. Blvd. Del Maestro, esq. Elias Piña,

C.P. 88710 Reynosa, TAMPS, México

e-mail: jnarvaez@ipn.mx

R. Rojas-Herrera

Facultad de Ingeniería Química, Universidad Autónoma de Yucatán, Periférico Nte. Km. 33.5, Tablaje Catastral 13615, Col, Chuburná de Hidalgo Inn, C.P. 97203 Mérida, YUC, México

L. Sánchez-Estudillo

Laboratorio de Biotecnología de Microalgas, Universidad del Mar. Ciudad Universitaria, Puerto Ángel, Distrito de San Pedro Pochutla, C.P. 70902 Oaxaca, México 